\title{
Construction of Knowledge Test to Measure the Knowledge on Recommended Groundnut Production Practices
}

\author{
R.Sureshverma ${ }^{1}$, G. Samuel ${ }^{2}$, I. Sreenivasa Rao ${ }^{3}$, Vidyasagar $^{4}$ and Srinivasa chary ${ }^{5}$
}

\begin{abstract}
The non-availability of a standardized scale to measure the farmers' knowledge level influenced the researchers to construct a test for measuring the knowledge on recommended groundnut production package of practices. Pertinent items were collected covering all aspects from the crop production guide developed by the Department of Agriculture, Govt. of Tamil Nadu \& Tamil Nadu Agricultural University. After getting jury opinion on the items, test index of item difficulty, index of item discrimination and point biserial correlation for the items were worked out. All these were taken in to account to arrive at the final scale. While administrating the knowledge test a respondent was given one mark for each correct answer and zero for wrong answer. Eleven (11) items were finally selected from a total of fifty five (55) items.
\end{abstract}

Keywords: Knowledge test; unreached farmers; recommended practices; Groundnut; Tamil Nadu.

\section{INTRODUCTION}

In the present study, knowledge was operationalized as the quantum of information known to the unreached farmers on recommended groundnut production package of practices in order to lead a sustainable life. A knowledge test was developed with eleven (11) items to measure the knowledge of unreached farmers on recommended practices. Each item was measured on two point continuum viz., correct and incorrect with ' 1 ' and ' 0 ' score respectively. The possible maximum and minimum scores to be obtained by unreached farmers were 11 and 0 respectively. The detailed procedure followed for the construction and standardization of the knowledge test is shown below.

\section{METHODOLOGY}

\section{Collection of items}

On perusal of relevant literature and discussion with the experts in extension \& biological sciences, a total of 74 items were collected focusing on various aspects of groundnut cultivation i.e., crop improvement, production and protection by referring to the crop production guide of the Department of Agriculture, Govt. of Tamil Nadu \& Tamil Nadu Agricultural University. Experts in the field of Agronomy and Agricultural Entomology of Prof. Jayashankar Telangana State Agricultural University, Hyderabad were consulted for screening, fine tuning and editing of the items. Based on the opinion of the scientists,

1. Ph. D Scholar, 2 and 3. Professors, Dept. of Agricultural Extension, 4. Professor, Agronomy, and 5. Assistant Professor, Statistics, College of Agriculture, Prof. Jayashankar Telangana State Agricultural University, Rajendra Nagar, Hyderabad, Telangana

Received : 16-08-2017; Accepted : 02-03-2018 
a total of fifty five (55) items were retained. These retained fifty five (55) items were then subjected to item analysis to have suitable items to be included in the final schedule based on the opinion of the respondents from non-sample area.

\section{Item analysis}

The item analysis was carried out in terms of three indices viz., item difficulty index, item discrimination index and point-biserial correlation. The index of item discrimination provides information on how well an item discriminates well informed respondents from poorly informed. Whereas item difficulty index indicates the extent to which an item was difficult. The main aim of calculating Point biserial correlation (rpbis) was to work out the internal consistency of the items i.e., the relationship of the total score to a dichotomized answer to any given item.

\section{Difficulty index $(P)$}

The selected items (55 items for groundnut) were administered to 60 non-sample respondents with two point continuum response for each statement. The scores allotted were one (1) for correct response and zero (0) for incorrect response. After computing the total score obtained for each of the 60 respondents on items, they were arranged in order from highest to lowest. Based on which the 60 respondents were then divided into six equal groups. These groups were labelled as G1, G2, G3, G4, G5 and G6 with 10 respondents in each group.

For the purpose of item analysis, the middle two groups G3 and G4 were eliminated keeping only four extreme groups with high and low scores. The index of 'Item difficulty' was worked out as the percentage of the respondents answering an item correctly. The items with ' $p$ ' values ranging from 30.0 to 70.0 were considered for the final selection of the knowledge test. For each item the correct answer was calculated to get the difficulty index. The results are presented in Table 1.

Total number of correct

Difficulty answers Index

Total number of respondents

\section{Discrimination Index (E 1/3)}

$\mathrm{S} 1, \mathrm{~S} 2$ and S5, S6 are the frequencies of correct answers in the groups G1, G2, G5 and $\mathrm{G} 6$ respectively. ' $\mathrm{N}$ ' is the total member of respondents of the sample selected for the item analysis that is 60 . The discrimination index varies from 0 to 1 . The items with discrimination index ranging from 0.30 to 0.70 were selected for the final test. This shows whether the items actually distinguished a well-informed person from one who is inadequately informed about the subject matter. The formula used was as below. This is the second criterion for item selection i.e., by the item discrimination index indicated by ' $E$ $1 / 3^{\prime}$ is calculated with the formula. The results are presented in Table 1.

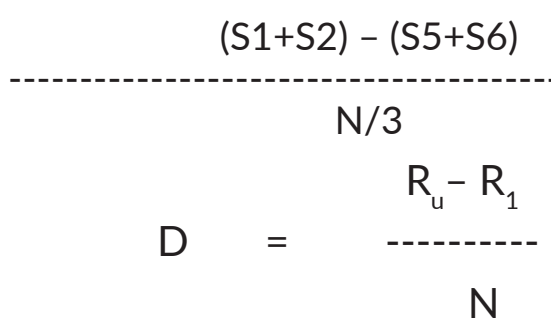


Construction of Knowledge Test to Measure the Knowledge on Recommended Groundnut Production Practices

Where,

$\begin{array}{lll}\mathrm{D} & : & \text { Discrimination Index } \\ \mathrm{R}_{\mathrm{u}} & : & \begin{array}{l}\text { Frequency of correct answers in } \\ \text { high knowledge group }\end{array} \\ \mathrm{R}_{1} & : \quad \begin{array}{l}\text { Frequency of correct answers in } \\ \text { low knowledge group }\end{array} \\ \mathrm{N} & : \quad \begin{array}{l}\text { Total number of respondents in } \\ \text { sample taken for item analysis }\end{array}\end{array}$

\section{Point Biserial Correlation $\left(r_{\mathrm{pbis}}\right)$}

The main aim of calculating point biserial correlation $\left(r_{p b i s}\right)$ was to work out the internal consistency of the items i.e., the relationship of the total score to a dichotomized answer to any given item. It is the correlation between right/wrong scores obtained by farmers in the non-sample area (Tiruvannamalai district of Tamil Nadu) on a given set of items. It is a special type of correlation between a dichotomous variable (the multiple-choice item score which is right or wrong, 0 or 1 ) and a continuous variable (the total score on the test ranging from 0 to the maximum number of multiple-choice items on the test). Like in all correlations, point-biserial values range from -1.0 to +1.0 . A large positive point-biserial value indicates that farmers with high scores on the overall test are also getting the item right and farmers with low scores on the overall test are getting the item wrong (Seemavarma,2015). The results are presented in table 1.

\section{Computation and interpretation of Point- Biserial Correlation}

The scores obtained by the farmers are arranged in matrix comprised of 55 items. The items were represented in the matrix columns from left to right and farmers represented as rows. A value of ' 1 ' was assigned to correct response and ' $O$ ' for wrong. The steps followed for computing Point-Biserial Correlationare 1. computed the total farmers score for each items 2.computed the total score minus each item score, 3.computed the Point-Biserial Correlation for each item using the 'CORREL' function.

A low point biserial implies that the farmer got the items incorrect. Therefore, items with low-point-biserial correlation values need further examination. It was reported by Seemavarma (2015) that the wordings, presentation or content of such items may explain the low point-biserial correlation. However, even if nothing appears visibly faulty with the items, it is recommended that they may be removed from scoring and future testing or may even be removed from final set of questions that may be included in the interview schedule. It is always recommended to use a minimum threshold value for the point-biserial correlation. A point biserial value of at least 0.15 is recommended (Seemavarma, 2015) though experience has shown that a very good number of items have point-biserial correlation value.

\section{Point biserial correlation: item discrimination}

The items to be considered for final inclusion into the interview schedule were based on its point biserial correlation value. Penn (2009) and McGahee and Ball (2009) have categorized items based on items point biserial correlation value i.e., the items which possess the point biserial correlation value 
of 0.20 and below said to be 'poor' and need revision, $0.20-0.29$ said to be 'fair', 0.30 0.39 said to be 'good' and $0.40-0.70$ said to be 'very good'. In the present study, the items which belong to 'very good' category (i.e., the items with point biserial correlation value of 0.40 - 0.70) were selected for final inclusion in the interview schedule.

Table 1.

Calculation for Selection of Suitable Knowledge Items for Groundnut Crop

\begin{tabular}{|c|c|c|c|c|c|c|c|c|c|}
\hline \multirow[t]{2}{*}{ SI. No. } & \multicolumn{4}{|c|}{$\begin{array}{l}\text { Frequencies of } \\
\text { correct answer of } \\
\text { respondents in four } \\
\text { extreme groups }\end{array}$} & \multirow[t]{2}{*}{$\begin{array}{c}\text { Total } \\
\text { frequencies } \\
\text { of correct } \\
\text { answers by all } \\
\text { six groups }\end{array}$} & \multirow[t]{2}{*}{$\begin{array}{l}\text { Percent } \\
\text { of giving } \\
\text { correct } \\
\text { responses }\end{array}$} & \multirow[t]{2}{*}{$\begin{array}{l}\text { Difficulty } \\
\text { index } \\
\text { (P) }\end{array}$} & \multirow[t]{2}{*}{$\begin{array}{c}\text { Discrimination } \\
\text { index } \\
\text { (E 1/3) }\end{array}$} & \multirow[t]{2}{*}{$r_{\text {pbis }}$} \\
\hline & G-1 & G-2 & G-5 & G-6 & & & & & \\
\hline 1 & 10 & 6 & 4 & 4 & 40 & 66.67 & 60.0 & 0.70 & 0.387 \\
\hline 2* & 10 & 10 & 0 & 2 & 32 & 53.33 & 55.0 & 0.65 & 0.611 \\
\hline $3^{*}$ & 10 & 9 & 3 & 4 & 40 & 66.67 & 65.0 & 0.65 & 0.484 \\
\hline 4 & 6 & 5 & 2 & 4 & 23 & 38.33 & 42.5 & 0.05 & 0.213 \\
\hline 5 & 8 & 7 & 8 & 2 & 34 & 56.67 & 62.5 & 0.05 & 0.189 \\
\hline 6 & 10 & 9 & 8 & 6 & 50 & 83.33 & 82.5 & 0.80 & 0.308 \\
\hline 7 & 8 & 9 & 2 & 1 & 30 & 50.00 & 50.0 & 0.75 & 0.437 \\
\hline 8* & 7 & 7 & 1 & 1 & 26 & 43.33 & 40.0 & 0.35 & 0.426 \\
\hline 9* & 9 & 10 & 4 & 3 & 34 & 56.67 & 65.0 & 0.35 & 0.425 \\
\hline 10 & 10 & 8 & 6 & 6 & 45 & 75.00 & 75.0 & 0.60 & 0.254 \\
\hline 11 & 9 & 6 & 3 & 3 & 27 & 45.00 & 52.5 & 0.30 & 0.330 \\
\hline $12^{*}$ & 9 & 10 & 7 & 2 & 45 & 75.00 & 70.0 & 0.70 & 0.446 \\
\hline 13 & 8 & 9 & 2 & 3 & 29 & 48.33 & 55.0 & 0.25 & 0.378 \\
\hline 14 & 6 & 7 & 8 & 4 & 35 & 58.33 & 62.5 & 0.40 & 0.074 \\
\hline 15 & 8 & 6 & 2 & 3 & 34 & 56.67 & 47.5 & 0.45 & 0.304 \\
\hline 16 & 5 & 3 & 1 & 4 & 14 & 23.33 & 32.5 & 0.10 & 0.196 \\
\hline 17 & 10 & 4 & 3 & 3 & 28 & 46.67 & 50.0 & 0.40 & 0.345 \\
\hline 18 & 10 & 6 & 0 & 6 & 31 & 51.67 & 55.0 & 0.50 & 0.330 \\
\hline 19 & 10 & 5 & 3 & 3 & 28 & 46.67 & 52.5 & 0.45 & 0.374 \\
\hline 20 & 9 & 8 & 2 & 4 & 35 & 58.33 & 57.5 & 0.65 & 0.308 \\
\hline 21 & 5 & 4 & 2 & 2 & 23 & 38.33 & 32.5 & 0.05 & 0.217 \\
\hline 22 & 8 & 5 & 3 & 5 & 26 & 43.33 & 52.5 & -0.10 & 0.172 \\
\hline 23 & 9 & 7 & 8 & 7 & 45 & 75.00 & 77.5 & 0.65 & 0.103 \\
\hline $24^{*}$ & 10 & 5 & 1 & 2 & 19 & 31.67 & 45.0 & 0.40 & 0.525 \\
\hline 25 & 6 & 7 & 3 & 4 & 28 & 46.67 & 50.0 & 0.30 & 0.197 \\
\hline
\end{tabular}


Construction of Knowledge Test to Measure the Knowledge on Recommended Groundnut Production Practices

\begin{tabular}{|c|c|c|c|c|c|c|c|c|c|}
\hline & \multicolumn{3}{|c|}{$\begin{array}{c}\text { Frequencies of } \\
\text { SI. No. }\end{array}$} & $\begin{array}{c}\text { Total } \\
\text { respondents in four } \\
\text { extreme groups }\end{array}$ & $\begin{array}{c}\text { Tequencies } \\
\text { of correct } \\
\text { answers by all } \\
\text { six groups }\end{array}$ & $\begin{array}{c}\text { Percent } \\
\text { of giving } \\
\text { correct } \\
\text { responses }\end{array}$ & $\begin{array}{c}\text { Difficulty } \\
\text { index } \\
\text { (P) }\end{array}$ & $\begin{array}{c}\text { Discrimination } \\
\text { index } \\
\text { (E 1/3) }\end{array}$ & r $_{\text {pbis }}$ \\
\hline $26^{*}$ & 9 & 8 & 6 & 1 & 39 & 65.00 & 60.0 & 0.55 & 0.491 \\
\hline 27 & 8 & 6 & 4 & 2 & 28 & 46.67 & 50.0 & 0.35 & 0.348 \\
\hline 28 & 9 & 5 & 3 & 4 & 24 & 40.00 & 52.5 & 0.40 & 0.311 \\
\hline $29^{*}$ & 9 & 5 & 5 & 1 & 25 & 41.67 & 50.0 & 0.50 & 0.412 \\
\hline 30 & 8 & 7 & 10 & 3 & 45 & 75.00 & 70.0 & 0.50 & 0.242 \\
\hline 31 & 8 & 7 & 3 & 2 & 35 & 58.33 & 50.0 & 0.35 & 0.381 \\
\hline 32 & 8 & 3 & 4 & 4 & 23 & 38.33 & 47.5 & -0.05 & 0.213 \\
\hline 33 & 9 & 7 & 8 & 4 & 42 & 70.00 & 70.0 & 0.55 & 0.239 \\
\hline 34 & 9 & 3 & 3 & 2 & 22 & 36.67 & 42.5 & 0.20 & 0.402 \\
\hline 35 & 8 & 3 & 3 & 5 & 30 & 50.00 & 47.5 & 0.15 & 0.156 \\
\hline 36 & 9 & 6 & 3 & 5 & 37 & 61.67 & 57.5 & 0.10 & 0.235 \\
\hline 37 & 10 & 6 & 8 & 5 & 47 & 78.33 & 72.5 & 0.55 & 0.287 \\
\hline $38^{*}$ & 9 & 7 & 4 & 1 & 28 & 46.67 & 52.5 & 0.30 & 0.426 \\
\hline 39 & 9 & 6 & 6 & 4 & 41 & 68.33 & 62.5 & 0.40 & 0.263 \\
\hline 40 & 10 & 7 & 4 & 3 & 26 & 43.33 & 60.0 & 0.70 & 0.391 \\
\hline 41 & 7 & 3 & 1 & 2 & 18 & 30.00 & 32.5 & 0.25 & 0.309 \\
\hline 42 & 9 & 4 & 3 & 2 & 30 & 50.00 & 45.0 & 0.00 & 0.350 \\
\hline 43 & 9 & 8 & 7 & 6 & 49 & 81.67 & 75.0 & 0.40 & 0.212 \\
\hline 44 & 10 & 6 & 5 & 4 & 38 & 63.33 & 62.5 & 0.70 & 0.324 \\
\hline 45 & 6 & 7 & 0 & 2 & 21 & 35.00 & 37.5 & 0.05 & 0.363 \\
\hline 46 & 10 & 6 & 9 & 3 & 44 & 73.33 & 70.0 & 0.50 & 0.328 \\
\hline 47 & 9 & 4 & 5 & 1 & 30 & 50.00 & 47.5 & 0.35 & 0.387 \\
\hline 48 & 8 & 5 & 2 & 4 & 27 & 45.00 & 47.5 & 0.15 & 0.180 \\
\hline 49 & 9 & 9 & 8 & 2 & 41 & 68.33 & 70.0 & 0.40 & 0.353 \\
\hline 50 & 9 & 8 & 8 & 2 & 46 & 76.67 & 67.5 & 0.20 & 0.411 \\
\hline 51 & 9 & 6 & 9 & 4 & 46 & 76.67 & 70.0 & 0.30 & 0.344 \\
\hline $52^{*}$ & 10 & 6 & 9 & 1 & 40 & 66.67 & 65.0 & 0.30 & 0.406 \\
\hline $53^{*}$ & 10 & 8 & 6 & 4 & 44 & 73.33 & 70.0 & 0.35 & 0.416 \\
\hline 54 & 8 & 8 & 8 & 3 & 43 & 71.67 & 67.5 & 0.65 & 0.301 \\
\hline 55 & 5 & 6 & 3 & 0 & 28 & 46.67 & 35.0 & 0.55 & 0.331 \\
\hline
\end{tabular}

* Items selected for final inclusion 


\section{Item selection}

The items with difficulty level indices ranging from 30.0 to 70.0 , discrimination indices ranging from 0.30 to 0.70 and the items with point biserial correlation ranging from 0.40 to 0.70 levels were selected finally to include in the interview schedule for assessing the level of knowledge of unreached farmers on recommended crop production package of practices. A total of 11 knowledge items for groundnut were finally selected (Table 2).

Thus, the finally selected knowledge test items comprised different types of questions viz., multiple choice questions, yes or no type questions, true or false, fill up the blanks and direct one word answer. The selected items with frequency of correct response, $\mathrm{P}, \mathrm{E} 1 / 3$ and Rpbis values were included in the scale.

\section{Reliability of Knowledge test}

According to Kerlinger

"Reliability is the accuracy or precision of measuring instrument". To know the reliability of the items the Split-Half method was followed.

\section{Split-Half Methodology}

The reliability of the scale was determined by split-half method. The selected items i.e., eleven (11) items were divided into two halves. The two halves were further administered separately to 30 unreached farmers in a nonsample area (Tiruvannamalai district of Tamil Nadu) The scores were subjected to product moment correlation test in order to find out the reliability of the scale. The half-test reliability co-efficient ( $r$ ) was 0.356 . Further, the reliability co-efficient of the whole test was computed using the Spearman Brown Prophecy formula (Singh, 1986) given below.

$$
\begin{aligned}
& \begin{array}{l}
\text { Reliability co-effi- } \\
\text { cient of whole test }
\end{array}= \\
& \begin{array}{c}
\text { 2x Reliability co- } \\
\text { efficient of half test }
\end{array} \\
& \begin{array}{c}
1+\text { Reliability co- } \\
\text { efficient of half test }
\end{array}
\end{aligned}
$$

The whole test reliability co-efficient of the whole test was computed using the Spearman Brown Prophecy worked out and the results were 0.526 for the items selected for groundnut crop. According to Singh (1986), when the mean scores of the two groups are of narrow range, reliability co-efficient of 0.50 or 0.60 would be sufficient. Hence, the constructed scale to assess unreached farmers knowledge was considered reliable.

\section{Validity of the test items}

The validity of the test items was tested by the method of correlation coefficient ( $r$ ) and content validity. The items which belonged to 'very good' category (i.e., the items with point biserial correlation value of 0.40 - 0.70) were considered to measure the knowledge of the unreached farmers on recommended crop production package of practices. Also the content validity of the knowledge test was derived from a long list of test items representing the whole universe on recommended crop production package of practices on groundnut.

It was assumed that the score obtained by administering the knowledge test of this study measures what was intended to 
measure. Thus, the knowledge test developed, exactly measures the knowledge of unreached farmers on recommended crop production package of practices of groundnut as it showed a greater degree of reliability and validity.

\section{FINDINGS AND DISCUSSION}

Table 2 represents the final knowledge items selected for assessing the knowledge level of farmers on recommended crop production package of practices on groundnut crop. The scale standardized may be directly used by a researcher for assessing knowledge level of farmers on recommended groundnut production of practices. The items selected finally using standard procedures includes different aspects of crop production and different form of questions viz., multiple choice questions, yes or no type questions, true or false and fill up the blanks and direct one word answer.

Table 2.

Knowledge Items Identified for Groundnut Crop

\begin{tabular}{|c|c|c|}
\hline $\begin{array}{l}\text { Sl. } \\
\text { No. }\end{array}$ & $\begin{array}{l}\text { Selected } \\
\text { questions }\end{array}$ & $\begin{array}{l}\text { Knowledge items for groundnut } \\
\text { (included in the interview schedule) }\end{array}$ \\
\hline 1 & $2^{*}$ & What is the blanket recommendation of nutrient for Groundnut \\
\hline 2 & $3^{*}$ & $\begin{array}{l}\text { At how many days after sowing, two hand weedings and hoeing are necessary } \\
\text { to control weeds if no herbicide is applied }\end{array}$ \\
\hline 3 & $8^{*}$ & $\begin{array}{l}\text { After application of which nutrient earthing up should be done } \\
\text { a.Gypsum b. Water c. Zinc sulphate d. none }\end{array}$ \\
\hline 4 & $9^{*}$ & $\begin{array}{l}\text { Which nutrient should be applied in the soil which is deficient in calcium and } \\
\text { sulphur? }\end{array}$ \\
\hline 5 & $12^{*}$ & What is the recommended spacing for groundnut? \\
\hline 6 & $24^{*}$ & How many days after sowing, life irrigation is needed? \\
\hline 7 & $26^{*}$ & $\begin{array}{l}\text { What is the important cultural operation to be carried out to provide medium } \\
\text { for the peg development? }\end{array}$ \\
\hline 8 & $29^{*}$ & $\begin{array}{l}\text { Appearance of pustules on the lower surface of leaf is the symptom of } \\
\text { a. Leaf spot b. rust c. early leaf spot d. none of the above }\end{array}$ \\
\hline 9 & $38^{*}$ & $\begin{array}{l}\text { What are the recommended management practices to overcome the problems } \\
\text { of termite in groundnut field? }\end{array}$ \\
\hline 10 & $52^{*}$ & What is the quantity of gypsum to be applied \\
\hline 11 & $53^{*}$ & $\begin{array}{l}\text { Do you agree that, seed treatment is to be done to overcome the problem of } \\
\text { stem rot? }\end{array}$ \\
\hline
\end{tabular}




\section{CONCLUSION}

The scale constructed following standard procedures may be used by the researchers for similar studies. The scale constructed will save the time of researchers working on similar lines.

\section{REFERENCES}

Kerlinger, F.N. (1973). Foundations of behavioral research. Holt, Rinehart and Winston. New York.

McGahee, T.W., \& Ball, J. (2009). How to read and really use an item analysis. Nurse
Educator, (34) 166-171.

Penn, B.K. (2009). Test item development and analysis. Presented at Creighton University School of Nursing Faculty Retreat, Omaha, Nebraska, US.

Seemavarma.(2015). Preliminary Item Statistics Using Point-Biserial Correlation and P-values, Education data System, Morgan Hill, California.

Singh, A.K. (1986). Tests, Measurement and Research Methods in behavioural Sciences. Tata Mcgraw-Hill Publishing Company Ltd., New Delhi. 